\title{
Potential linkages between mineral magnetic measurements and urban roadside soil pollution (Part 2).
}

\author{
C.J. Crosby ${ }^{1}$, M.A. Fullen ${ }^{2}$, C.A. Booth ${ }^{3}$ \\ Received (in $X X X, X X X)$ Xth $X X X X X X X X X 20 X X$, Accepted $X$ th $X X X X X X X X X 20 X X$ \\ ${ }_{5}$ DOI: 10.1039/b000000x
}

Use of mineral magnetic concentration parameters $\left(\chi_{\mathrm{LF}}, \chi_{\mathrm{ARM}}\right.$ and SIRM) as a potential pollution proxy for soil samples collected from Wolverhampton (UK) is explored. Comparison of soil-related analytical data by correlation analyses between each magnetic parameter and individual geochemical classes (i.e. $\mathrm{Fe}, \mathrm{Pb}, \mathrm{Ni}, \mathrm{Zn}, \mathrm{Cd})$, are reported. $\chi_{\mathrm{LF}}, \chi_{\mathrm{ARM}}$ and SIRM parameters reveal significant $(p<0.001 \mathrm{n}=60)$, 10 strong $(\mathrm{r}=0.632-0.797)$, associations with $\mathrm{Fe}, \mathrm{Cu}, \mathrm{Zn}$ and $\mathrm{Pb}$. Inter-geochemical correlations suggest anthropogenic influences, which is supported by low $\chi_{\mathrm{FD}} \%$ measurements that infer an influence of multidomain mineralogy are indicative of anthropogenic combustion processes. Results indicate mineral magnetic measurements could potentially be used as a geochemical indicator for soils in certain environments and/or specific settings that are appropriate for monitoring techniques. The mineral

15 magnetic technique offers a simple, reliable, rapid, sensitive, inexpensive and non-destructive approach that could be a valuable pollution proxy for soil contamination studies.

\section{Introduction}

Urban sediments are an important source of pollution material in urban environments, forming a sink for vehicle exhaust, 20 weathered material, soil and as a source of atmospheric particulate matter (PM). ${ }^{1}$ Soil contamination by heavy metals, ${ }^{2}$ radionuclides, ${ }^{3}$ or persistent organic pollutants, such as polycyclic aromatic hydrocarbons (PAHs), ${ }^{4}$ and polychlorinated biphenyls (PCBs), ${ }^{5}$ are also important public health concerns. ${ }^{6,7}$ Urban 25 sediment is composed of a wide range of grains, which are typically dominated by quartz, clay and carbonates, mainly due to underlying parent material. ${ }^{1}$ In addition, abundant anthropogenic grains are present, including glass particles from industrial processes and high temperature combustion, metal slags, cement 30 grains, metallic fragments and iron oxide particles. ${ }^{1}$

Assessment of the extent and severity of soil contamination requires thorough investigation before remediation can proceed. ${ }^{8,9}$ However, soil-related analysis can be time consuming and expensive. In the study of sediments the most widely used 35 techniques used are: Inductively Coupled Plasma-Mass Spectroscopy (ICP-MS). ${ }^{10-15}$ Inductively Coupled Plasma-Atomic Emission Spectroscopy (ICP-AES), ${ }^{16-18}$ Scanning Electron Microscope (SEM) techniques, ${ }^{19,20}$ sequential extraction methods, ${ }^{20-23}$ Graphite Furnace Atomic Absorption Spectrometry ${ }_{40}$ GFAAS, ${ }^{11}$ Flame Atomic Absorption Spectrometry (FAAS), ${ }^{21}$ and X-Ray Fluorescence (XRF) spectrometry. 10,19,24,25 Many studies investigating the geochemical composition of sediments have successfully revealed heavy metal concentrations, with a range of intensities indicating local and regional pollution. 45 Traditional geochemical methods (e.g. AAS, ICP-MS) are relatively complex, time-consuming and expensive with cost of instrumentation and additional expertise required for successful operation. These instruments are bound to static locations and require specific laboratory environments and are therefore 50 unsuitable for mapping or monitoring of large-scale pollution. Where a pollution proxy can be measured efficiently (that is, shorter analysis time or lower cost), it can offer potential advantages. To assess the suitability of an efficient pollution proxy, it is necessary that the nature of the relationship between ${ }_{55}$ the investigated parameters follow predictable patterns (like those of trace metals, radionuclides and poly-chlorinated biphenyls (PCBs)).

Mineral magnetic measurements are now considered a routine form of analysis when investigating the compositional properties 60 of rocks, sediments and soils. ${ }^{26}$ This technique has been applied to several depositional environments including marine, estuarine, and fluvial. ${ }^{27}$ Recently a magnetic approach has been suggested for particle size proxy purposes. ${ }^{27-30}$ In the study of coastal sediments, ${ }^{28}$ marine, estuarine and fluvial sediments, ${ }^{27,31}$ soil, ${ }^{32}$ ${ }_{65}$ road deposited sediments, ${ }^{33,34}$ and roadside dust on tree leaves, ${ }^{35}$ mineral magnetic methods have been used as indicators of particle size and pollution. Many studies have explored relationships between mineral magnetic measurements and the physicochemical properties of soils, sediments and dusts. ${ }^{34,33,36-38}$ 70 Based on these investigations, mineral magnetic measurements have been identified as a suitable proxy for geochemical, radioactivity, organic matter content and particle size data. $^{27,28,30,31,37-41}$

Anthropogenic particles in urban settings display distinctive 75 magnetic properties such as magnetic enhancement. ${ }^{26}$ Magnetic particles produced from anthropogenic processes have increased in abundance within the environment since the industrial revolution ( $\operatorname{circa} 19^{\text {th }}$ century), primarily from the combustion of fossil fuels. ${ }^{42-44}$ Iron occurs as an impurity in fossil fuels, which 80 unburned, has low magnetization. ${ }^{45}$ However, on combustion (industrial, domestic, vehicular) carbon and organic material are lost by oxidation and highly magnetic iron oxide (magnetite and haematite) spherules are produced. ${ }^{42,46,47}$ Combustion temperature and fuel type determines the magnetic grain size, mineralogy and 85 concentration of these particulates. ${ }^{20,45,48}$ Some studies have found strong relationships between certain magnetic properties (magnetic susceptibility $\chi_{\mathrm{LF}}$ ) and heavy metal concentrations. ${ }^{25,30,42}$ Despite these advances, the approach of 
using mineral magnetic properties in the study of environmental pollution has not been fully explored.

Compared with other geochemical techniques, mineral magnetic methods are relatively quick and simple to prepare and 5 analyse. ${ }^{49}$ Measurements of magnetic susceptibility $\left(\chi_{\mathrm{LF}}\right)$ can be made in $\sim 1$ minute, within either a laboratory or field environment. ${ }^{27}$ This allows relatively large data sets to be acquired, adding statistical weight to any data collected. ${ }^{49}$ Initial costs of magnetic susceptibility $\left(\chi_{\mathrm{LF}}\right)$ instrumentation are low 10 (Bartington MS2 susceptibility meter and sensor £3,960) when compared to XRF and ICP-MS.

It is timely for innovative technologies to be considered as an alternative, or in tandem, to those already employed to determine urban soil pollution. Ideally, they need to be rapid, reliable, 15 dynamic and inexpensive. To assess the suitability of any analytical technique as an efficient pollution proxy, it is necessary that the nature of the relationship between the proposed parameters follow predictable patterns. To date, most work has not examined the extent to which mineral magnetic parameters 20 are reliable indicators of differences in soil contaminants. This paper presents the second part of a study describing mineral magnetic methods as a pollution proxy in urban soils. The first part presented in Crosby et al. ${ }^{50}$ and further referred to as 'Part 1', specifically investigated the potential for particle size indication 25 in urban soils. Part 2 will further investigate the potential of mineral magnetic measurements as a geochemical pollution proxy in urban soils.

\section{Materials and methods}

A horizon, topsoil $(0-20 \mathrm{~cm}$ depth) samples $(\mathrm{n}=60)$ were 30 collected from the City of Wolverhampton's (West Midlands UK (Fig.1)) main Ring Road (A4150). The main road encircles the city centre and is approximately $3.1 \mathrm{Km}$ long with traffic counts of $\sim>15,000$ vehicles per day. Samples were collected along the A4150 covering the full circumference of the main road (sample 35 points $\mathrm{n}=30$ ) (Fig. 1.) Samples were collected $\sim 50 \mathrm{~m}$ along both sides of the central reservation to represent directional traffic (sample points $\mathrm{n}=30 \times 2 ; \mathrm{tn}=60$ ). Topsoil was transferred to clean, pre-labelled, self-seal, airtight plastic bags. In the laboratory, samples were visibly screened to remove macroscopic 40 traces of hair, animal and plant matter.

\section{Magnetic analyses}

All samples were subject to the same preparation and analysis procedure. $^{27,49}$ Samples were dried $\left(<40{ }^{\circ} \mathrm{C}\right)$, weighed, packed

45 into $10 \mathrm{ml}$ plastic pots and immobilized with clean sponge foam and tape prior to analysis. Initial, low-field, mass-specific, magnetic susceptibility $(\chi)$ was measured using a Bartington MS2 susceptibility meter. By using a MS2B sensor, low and high frequency susceptibility was measured $\left(\chi_{\mathrm{LF}} / \chi_{\mathrm{HF}}\right)$. $\chi_{\mathrm{LF}}$ values are 50 roughly proportional to the concentration of ferrimagnetic minerals within a sample. The resultant $\chi_{\mathrm{LF}}$ and $\chi_{\mathrm{HF}}$ can be used to show frequency dependent susceptibility $\left(\chi_{\mathrm{FD} \%}\right)$ and is a measure of the occurrence of very fine magnetic domains on the superparamagnetic (SP) to stable single domain (SSD) and multi 55 domain (MD) boundary and is a good indicator of anthropogenic source (Fig.2). Anhysteretic Remanence Magnetisation (ARM) was induced with a peak alternating field of $100 \mathrm{mT}$ and small steady biasing field of $0.04 \mathrm{mT}$ using a Molspin A.F. demagnetiser. The resultant remanence created within the 60 samples was measured using a Molspin 1A magnetometer and the values converted to give the mass specific susceptibility of ARM $\left(\chi_{\text {ARM }}\right)$. The samples were then demagnetized to remove the induced ARM and exposed to a series of successively larger field sizes up to a maximum 'saturation' field of $800 \mathrm{mT}$, followed by 65 a series of successively larger fields in the opposite direction (backfields), generated by two Molspin pulse magnetisers (0-100 and 0-800 mT). After each 'forward' and 'reverse' field, sample isothermal remanent magnetisation (IRM) was measured using the magnetometer.

70

Fig.1 Map showing Wolverhampton Ring Road study area $(n=60)$.

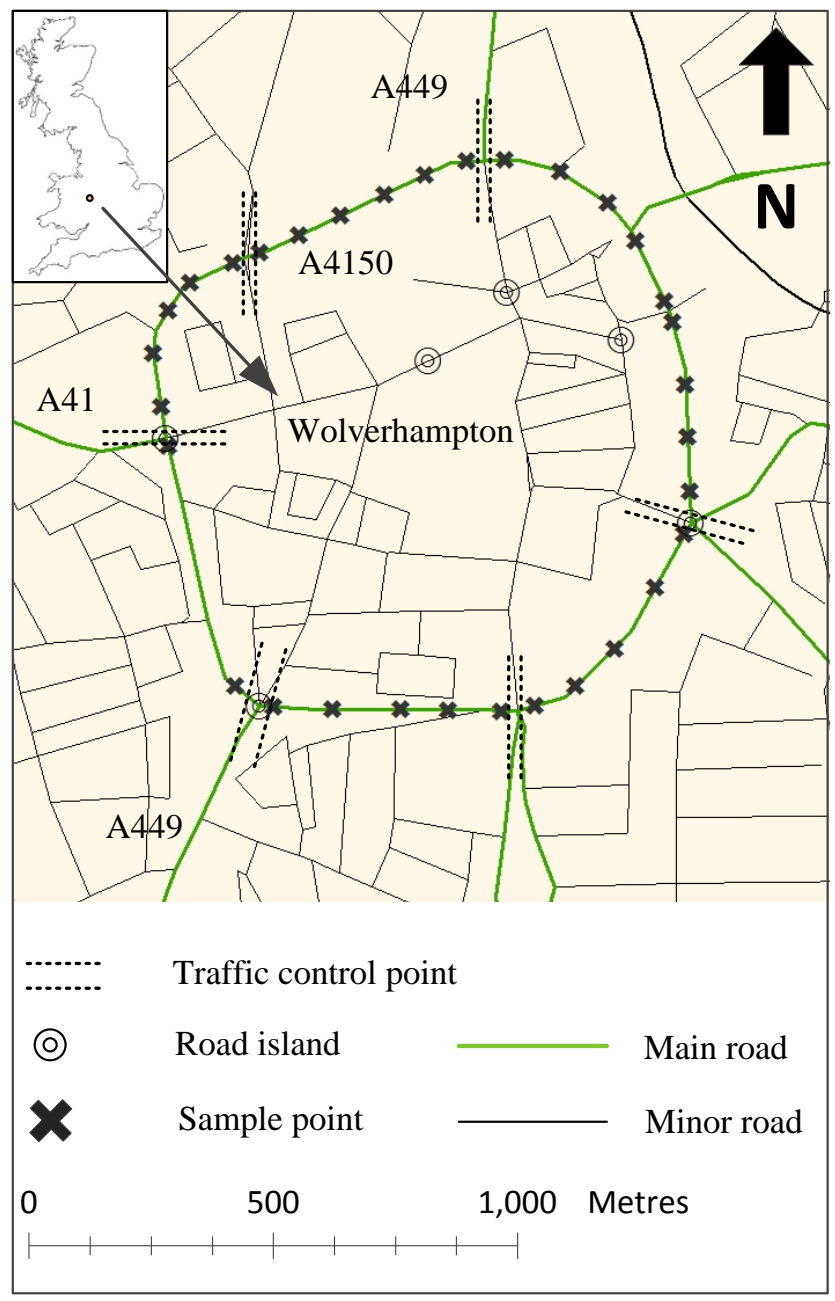




\section{Geochemical analyses}

All samples were subject to the same textural preparation and analysis procedure..$^{25,51}$ Concentrations of elements were determined by using isotope source X-ray fluorescence (XRF) 5 analysis using an ARL 8410 XRF spectrometer. Boyle, ${ }^{51}$ reported that total concentrations of elements can be determined in soils and sediments with sufficient accuracy using XRF techniques. $\mathrm{XRF}$ analysis has high precision with short analysis time and minimal handling of samples. Prior to measurements, the 10 instrument was calibrated using a range of reference materials.

\section{Results and discussion}

\section{Mineral magnetic concentration and spatial variation}

Mineral magnetic properties of Wolverhampton Ring Road top 15 soil samples are summarized in Table 1. The Wolverhampton Ring Road soil samples contain moderate to high concentrations of magnetic minerals $\left(\chi_{\mathrm{LF}} \quad 4.84-58.46 \quad \mathrm{x} \quad 10^{-7} \mathrm{~m}^{3} \mathrm{~kg}^{-1}\right.$; $\chi_{\text {ARM }}$ 0.18-1.0 x $10^{-7} \mathrm{~m}^{3} \mathrm{~kg}^{-1}$; SIRM 61.41-855.30 x $10^{-5} \mathrm{Am}^{2} \mathrm{~kg}^{-1}$ ), when compared to other urban soil studies. ${ }^{52,53} \chi_{\mathrm{LF}}$ varies spatially 20 across the sampling area, with high concentrations to the south west and directly east of the city centre (Fig. 3a (Fig.3 and 5 were generated by interpolating data with ARC view GIS v 10)). There appears to be bands of high and low concentration of magnetic material across the sampling area. Low concentrations are to the 25 north, with an area of high and then low as you move east along the ring road (Fig.3a). Low-frequency magnetic susceptibility $\left(\chi_{\mathrm{LF}}\right)$ represents the total contribution of ferromagnetic minerals. Susceptibility of Anhysteretic Remanent Magnetisation $\left(\chi_{\mathrm{ARM}}\right)$ is roughly proportional to the concentration of magnetic grains of 30 stable single domain size (e.g. $\sim 0.03-0.06 \mu \mathrm{m}$ ). Saturation Isothermal Remanent Magnetisation (SIRM) is related to concentrations of all remanence-carrying minerals in the sample, but is also dependent upon the assemblage of mineral types and their magnetic grain size. ${ }^{49}$

35 The $\chi_{\mathrm{FD}}$ results suggest the presence of MD and SP grain assemblages (Fig.2). $\chi_{\mathrm{FD} \%}$ for top soils in England have been found to display a mean of $4.1 \% .^{54}$ This suggests mean soil

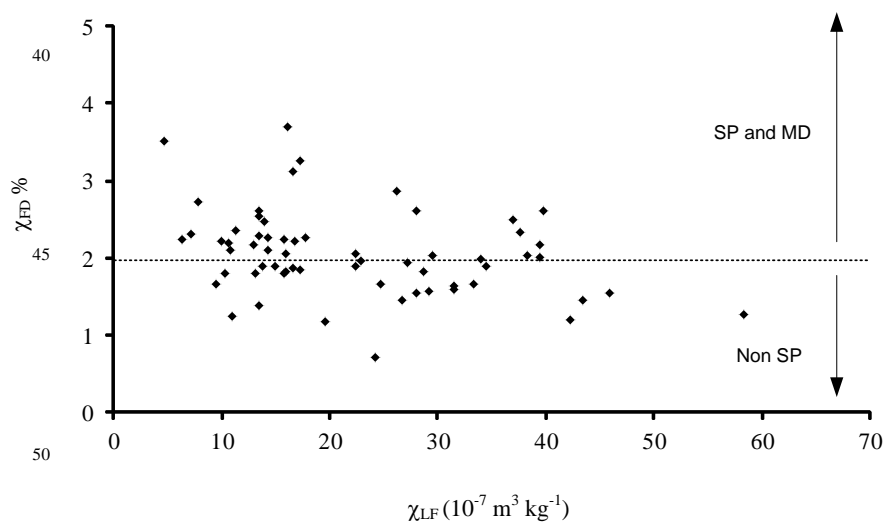

Fig. $2 \chi_{\mathrm{LF}}$ vs $\chi_{\mathrm{FD}} \%$ for Wolverhampton Ring Road soils. Non superparamagnetic, superparamagnetic and multi-domain boundaries as 55 defined by Dearing in Walden et al. ${ }^{49}$
Table 1 Mineral magnetic data for Wolverhampton ring road soils ( $n=60$ samples)

\begin{tabular}{ccccc}
\hline & $\chi_{\mathrm{LF}}$ & $\chi_{\mathrm{ARM}}$ & $\mathrm{SIRM}$ & $\chi_{\mathrm{FD}}$ \\
\hline Units & $10^{-7} \mathrm{~m}^{3} \mathrm{~kg}^{-1}$ & $10^{-7} \mathrm{~m}^{3} \mathrm{~kg}^{-1}$ & $10^{-5} \mathrm{Am}^{2} \mathrm{~kg}^{-1}$ & $\%$ \\
\hline Mean & 22.00 & 0.44 & 291.65 & 2.03 \\
Max & 58.46 & 1.00 & 855.3 & 3.67 \\
Min & 4.84 & 0.18 & 61.41 & 0.69 \\
Range & 53.62 & 0.82 & 793.89 & 2.97 \\
SD & 11.69 & 0.19 & 164.93 & 0.54 \\
CV & 0.53 & 0.43 & 0.57 & 0.27 \\
\hline
\end{tabular}

60 characteristics for the UK are predominantly superparamagnetic and naturally derived from weathering and erosion of background geologies. The Wolverhampton soil samples show considerably lower $\chi_{\mathrm{FD}}$ mean values when compared $(2.03 \%$ (Table 1$)$. Frequency dependent susceptibility $\left(\chi_{\mathrm{FD}}\right)$ measurements have ${ }_{65}$ previously been used to estimate magnetic grain sizes and potential sources of magnetic materials. ${ }^{20,54}$ High $\chi_{\mathrm{FD} \%}$ results

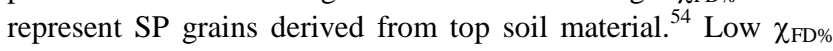
measurements are indicative of predominantly MD magnetic grain size assemblages. Coarse MD grains contribute notably to a 70 depression of high frequency susceptibility, therefore the closer the $\chi_{\mathrm{FD}}$ to zero the more MD assemblages are expected to dominate the sample. Low MD assemblages are common in polluted and urban soils, due to anthropogenic $\mathrm{Fe}$ input from combustion and industrial processes. Soil generally contains a 75 high concentration of naturally derived material, due to the nature of MD assemblages and high concentrations of $\chi_{\mathrm{LF}}$ attributed to anthropogenic inputs, the soil samples here show specific signatures attributed to artificial input. The resultant Ring Road soils exhibit high $\chi_{\mathrm{LF}}$ and low $\chi_{\mathrm{FD}}$ values due to potential 80 ferromagnetic loading and a high proportion of coarse grained minerals. These results correspond with Manchester concentrations, ${ }^{20}$ with low $\chi_{\mathrm{FD}}$ (mean $\left.2 \%\right)$ and high $\chi_{\mathrm{LF}}\left(27 \times 10^{-7}\right.$ $\left.\mathrm{m}^{3} \mathrm{~kg}^{-1}\right)$. Parent geologies beneath the selected soils are sedimentary in nature and suggest primary ferromagnetic 85 minerals from weathering are unlikely to make significant contribution to susceptibility values. ${ }^{55}$ However, natural soil material can dilute these values. Previous studies have noted increased concentrations of magnetic minerals in urban areas, ${ }^{20,56}$ which can be directly related to anthropogenic activity. ${ }_{90}$ Combustion of fossil fuels are known to produce large crystals of MD state. ${ }^{57}$ Blundell et al. ${ }^{56}$ reported magnetic enhancement in locations with current and historic anthropogenic activity. High concentrations of $\chi_{\mathrm{LF}}$ found within UK conurbations are expected to be derived from anthropogenic magnetic enhancement. ${ }_{95}$ Moreno et al. ${ }^{58}$ and Sheng-Gao et al. ${ }^{59}$ indicated high mineral magnetic concentrations and larger domain sizes of magnetic particles alongside roads with high volumes of vehicle traffic. The results of Wolverhampton soil samples suggested this may be the case in the study due to the magnetic characteristics and 100 proximity of samples to the ring road. 

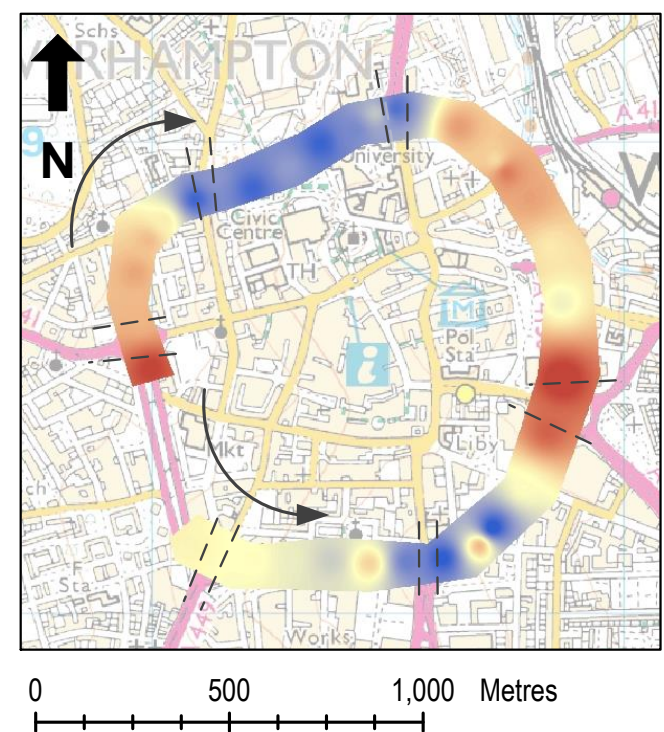

(a)
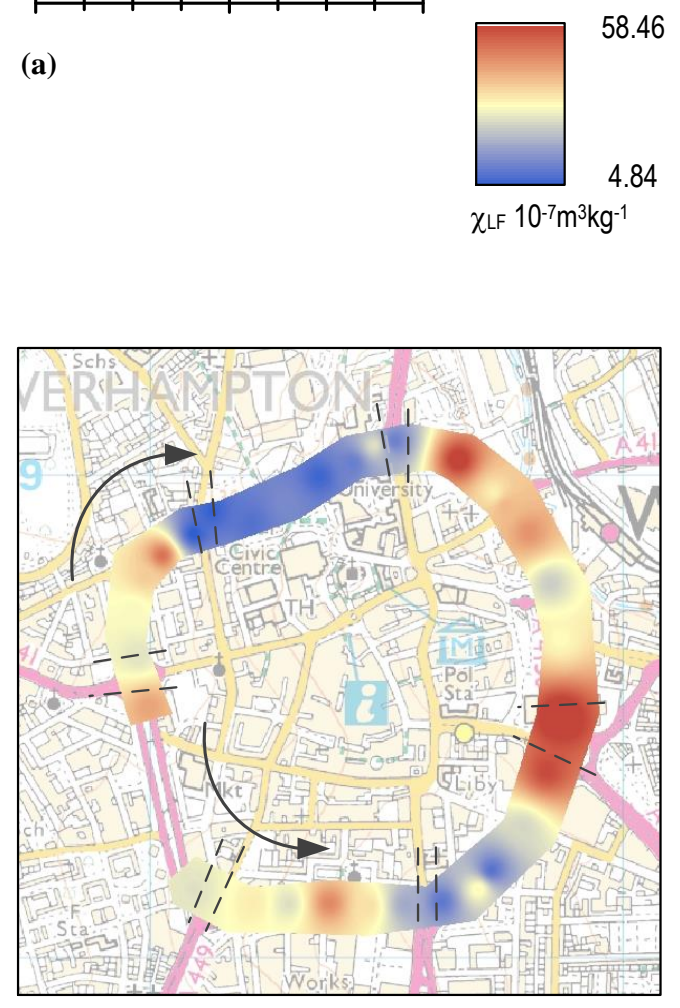

(c)

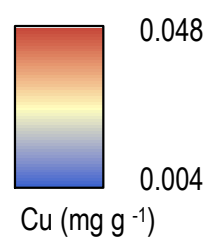

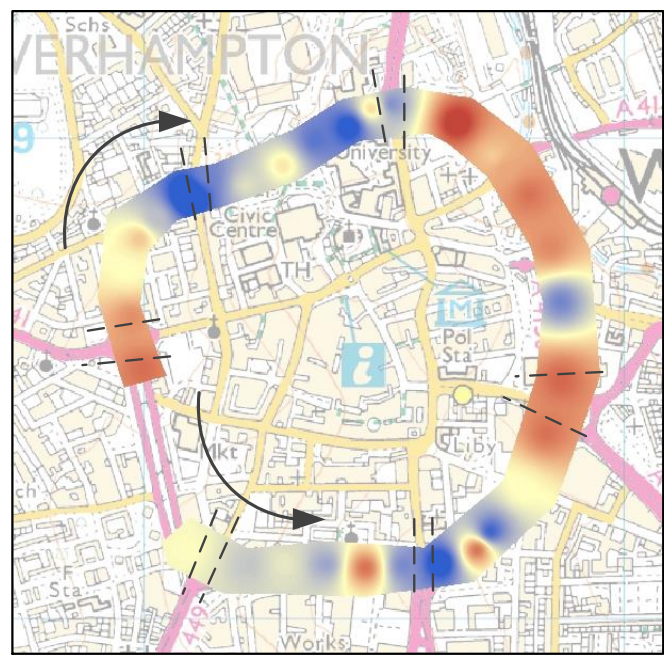

(b)
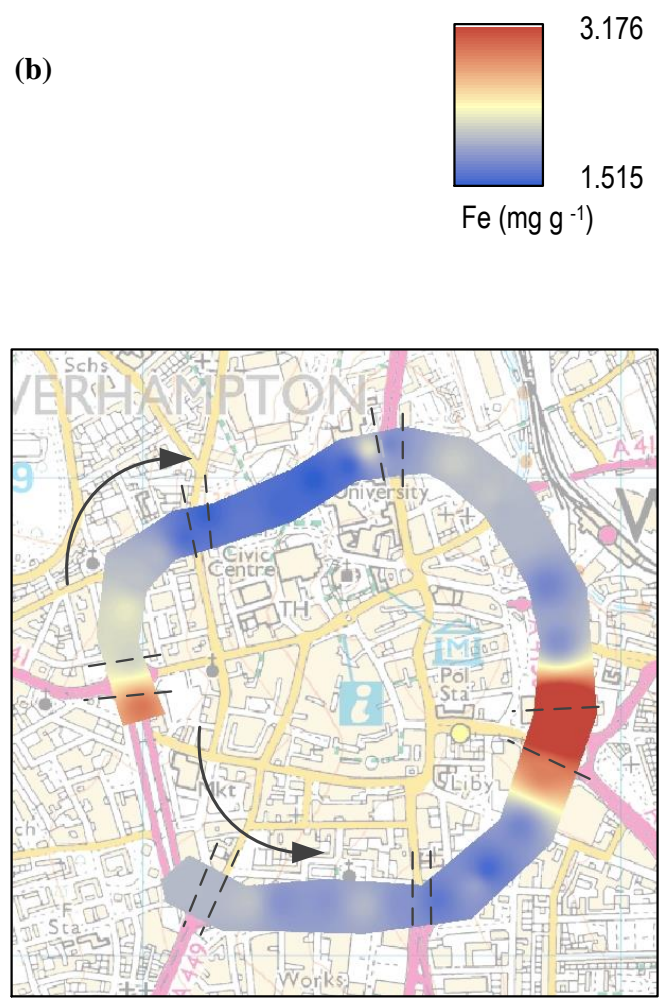

(d)

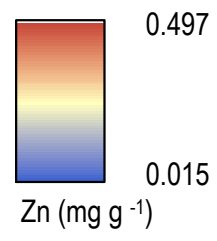

0.015

Fig. 3 Spatial distribution of a) $\chi_{\mathrm{LF}}$, b) $\mathrm{Fe}, \mathrm{c}$ ) $\mathrm{Cu}$ and d) $\mathrm{Zn}$ for Wolverhampton Ring Road soils. 
Table 2 Geochemical data $\left(\mathrm{mg} \mathrm{g}^{-1}\right)$ for Wolverhampton Ring Road soils ( $\mathrm{n}=60$ samples)

\begin{tabular}{llllllllllll}
\hline & $\mathrm{Fe}$ & $\mathrm{Cu}$ & $\mathrm{Zn}$ & $\mathrm{Mn}$ & $\mathrm{Pb}$ & $\mathrm{Ni}$ & $\mathrm{Cd}$ & $\mathrm{Si}$ & $\mathrm{Ti}$ & $\mathrm{Ca}$ \\
\hline Units & $\mathrm{mg} \mathrm{g}^{-1}$ & $\mathrm{mg} \mathrm{g}^{-1}$ & $\mathrm{mg} \mathrm{g}^{-1}$ & $\mathrm{mg} \mathrm{g}^{-1}$ & $\mathrm{mg} \mathrm{g}^{-1}$ & $\mathrm{mg} \mathrm{g}^{-1}$ & $\mathrm{mg} \mathrm{g}^{-1}$ & $\mathrm{mg} \mathrm{g}^{-1}$ & $\mathrm{mg} \mathrm{g}^{-1}$ & $\mathrm{mg} \mathrm{g}^{-1}$ & $\mathrm{mg} \mathrm{g}^{-1}$ \\
\hline Mean & 2.509 & 0.017 & 0.059 & 0.017 & 0.017 & 0.002 & 0.002 & 15.716 & 0.193 & 1.323 & 1.050 \\
Max & 3.716 & 0.048 & 0.497 & 1.292 & 0.043 & 0.005 & 0.008 & 20.700 & 0.247 & 5.970 & 1.525 \\
Min & 1.515 & 0.004 & 0.015 & 0.010 & 0.004 & 0.001 & 0.001 & 7.645 & 0.118 & 0.525 & 0.581 \\
Range & 2.201 & 0.044 & 0.482 & 1.282 & 0.039 & 0.004 & 0.007 & 13.055 & 0.129 & 5.445 & 0.944 \\
SD & 0.420 & 0.010 & 0.067 & 0.252 & 0.009 & 0.001 & 0.002 & 2.664 & 0.028 & 0.773 & 0.196 \\
CV & 0.167 & 0.588 & 1.136 & 0.803 & 0.529 & 0.500 & 1.000 & 0.170 & 0.145 & 0.584 & 0.187 \\
\hline
\end{tabular}

Geochemical results for Wolverhampton Ring Road top soil 5 samples are summarized in Table 2. Wolverhampton Ring Road soil samples contain moderate levels of $\mathrm{Fe}, \mathrm{Pb}, \mathrm{Ni}, \mathrm{Cu}$ and $\mathrm{Cd}$ when compared to other studies, ${ }^{20,23,37,60}$ with noatble variation between sites. Higher $\mathrm{Fe}$ and $\mathrm{Cu}$ concentrations are found to the north east and west of the City Centre (Figure $3 b \mathrm{c}$ ). High 10 concentrations of $\mathrm{Cu}\left(\max =0.048 \mathrm{mg} \mathrm{g}^{-1}\right)$ are also found to the west and south of the city centre (Figure 3c). High concentrations of $\mathrm{Zn}\left(\max =0.497 \mathrm{mg} \mathrm{g}^{-1}\right)$ are located directly to the east of the Ring Road and appear to be associated with the traffic island located at this position (Figure 3d). The 15 Wolverhampton Ring Road samples are dominated by Si (mean $15.716 \mathrm{mg} \mathrm{g}^{-1}$ ), $\mathrm{Fe}$ (mean $2.509 \mathrm{mg} \mathrm{g}^{-1}$ ) and $\mathrm{Ca}$ (mean $1.323 \mathrm{mg}$ $\mathrm{g}^{-1}$ ). Heavy metal concentrations of $\mathrm{Fe}, \mathrm{Pb}, \mathrm{Zn}$ and $\mathrm{Cu}$ are comparable with other urban soil studies. Concentrations of $\mathrm{Fe}$ are similar to those of Manchester, ${ }^{20}$ Buenos Aires, ${ }^{61}$ and ${ }_{20}$ Wuhan. ${ }^{60}$ Whereas, concentrations of $\mathrm{Pb}, \mathrm{Zn}$ and $\mathrm{Cu}$ are similar to those found in Birmingham (UK), ${ }^{23}$ Luanda (Angola), ${ }^{12}$ and Seoul (Korea). ${ }^{62}$ In contrast, mineral magnetic concentrations $\left(\chi_{\mathrm{LF}}\right)$ differ between soil and road dust due to the diluting effects of soil geochemistry, ${ }^{55}$ (enhanced silica concentrations) and are 25 generally not suitable for concentration comparison. Road dusts generally have shorter residence times and have been reported to display concentrated magnetic material in urban areas ${ }^{20,37}$.

Fig. 4a shows Spearman's rank correlation coefficient values (rs) between $\mathrm{Fe}$ and $\chi_{\mathrm{LF}}$, other selected mineral magnetic and 30 geochemistry parameters are shown in Table 3a. Moderate to strong positive correlations $(p<0.001)$ exist between each mineral magnetic parameter and specific elements $(\mathrm{Fe}, \mathrm{Cu}, \mathrm{Zn}$ and $\mathrm{Pb})(0.680$ to 0.885$)$. These elements are of particular importance to urban soil and sediment studies, due to 35 contributions from anthropogenic sources. Several studies have identified mineral magnetic and geochemical linkages. ${ }^{32,58,63-66}$ Strong relationships have been found with anthropogenicallyproduced particles ( $\mathrm{Mn}, \mathrm{Cu}, \mathrm{Fe}, \mathrm{Ni}, \mathrm{Zn}$ and $\mathrm{Pb}^{32,58,63,66,}$ Wang et al. ${ }^{67}$ found moderate correlations $(p<0.01)$ between heavy metals ${ }_{40}(\mathrm{Fe}, \mathrm{r}=0.770 ; \mathrm{Zn}, \mathrm{r}=0.481 ; \mathrm{Cu}, \mathrm{r}=0.464 ; \mathrm{Mn}, \mathrm{r}=0.546 ; \mathrm{Pb}, \mathrm{r}$ $=0.458)$ and $\chi_{\mathrm{LF}}$. Schmidt et al. ${ }^{32}$ found strong correlations between $\chi_{\mathrm{LF}}$ and heavy metals, when $\chi_{\mathrm{LF}}$ was found at sites with concentrations $>17.6 \times 10^{-7} \mathrm{~m}^{3} \mathrm{~kg}^{-1}$. Beckwith et al. ${ }^{63}$ and Schmidt et al. ${ }^{32}$ found this relationship was due to the enhanced magnetic 45 signature of the samples, which indicated anthropogenic sources.

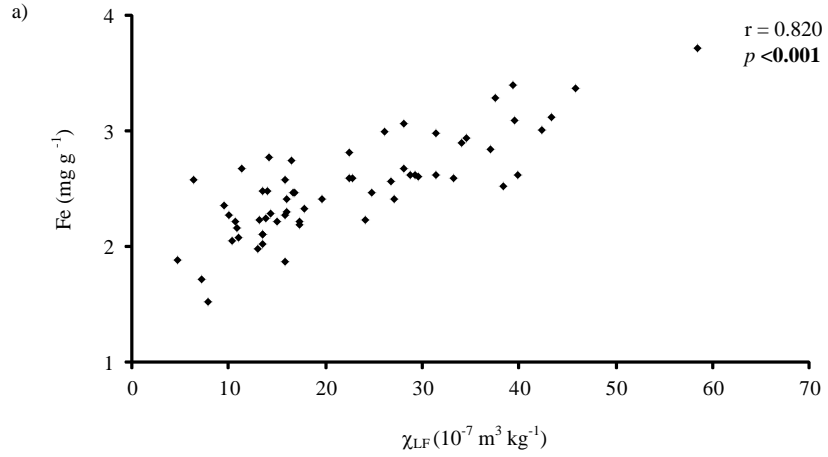

b)
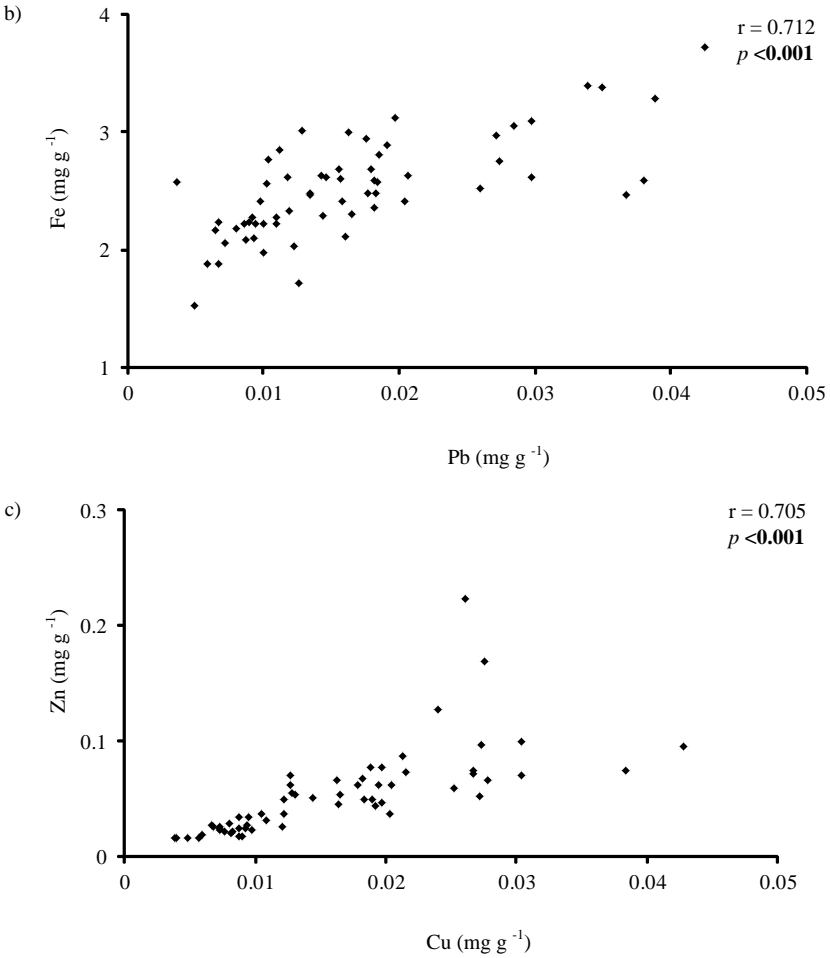

50

Fig. 4 Correlation plots of a) $\mathrm{Fe}$ vs $\chi_{\mathrm{LF}}$; b) $\mathrm{Fe}$ vs $\mathrm{Pb}$ and c) $\mathrm{Zn}$ vs $\mathrm{Cu}$ for Wolverhampton Ring Road soils $(n=60)$. 
Table 3 Pearson's correlation coefficients ( $\mathrm{r}$ ) between; (a) mineral magnetic concentration and geochemical parameters for Wolverhampton Ring Road top soils and (b) inter geochemical parameters (* $p<0.05$; ** $p<0.01$; *** $p<0.001$; NS = Not Significant $(n=60$ samples)).

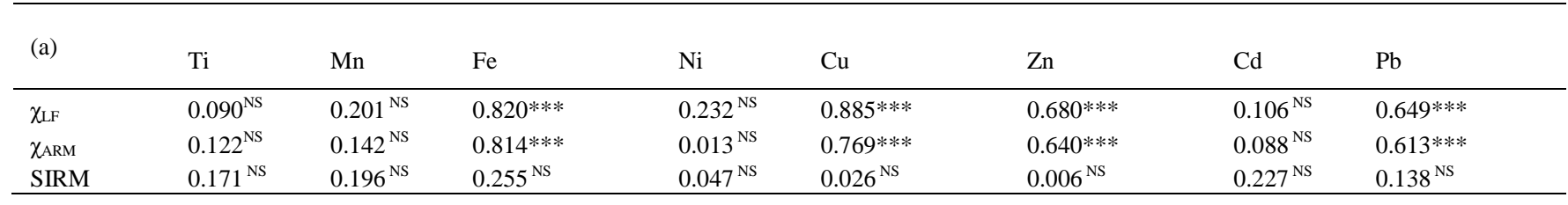

\begin{tabular}{lllllll} 
(b) & $\mathrm{Ti}$ & $\mathrm{Mn}$ & $\mathrm{Fe}$ & $\mathrm{Ni}$ & $\mathrm{Zn}$ & \\
\hline $\mathrm{Mn}$ & $0.526^{* *}$ & & & & \\
$\mathrm{Fe}$ & $0.430^{*}$ & $0.607^{* * *}$ & & & \\
$\mathrm{Ni}$ & $0.355^{*}$ & $0.397^{*}$ & $0.756^{* * *}$ & & & \\
$\mathrm{Cu}$ & $0.010^{\mathrm{NS}}$ & $0.376^{*}$ & $0.746^{* * *}$ & $0.710^{* * *}$ & & $0.072^{\mathrm{NS}}$ \\
$\mathrm{Zn}$ & $0.545^{* *}$ & $0.358^{*}$ & $0.637^{* * *}$ & $0.586^{* *}$ & $0.705^{* * *}$ & $0.029^{\mathrm{NS}}$ \\
$\mathrm{Cd}$ & $0.415^{*}$ & $0.056^{\mathrm{NS}}$ & $0.052^{\mathrm{NS}}$ & $0.232^{\mathrm{NS}}$ & $0.145^{\mathrm{NS}}$ & $0.634^{* * *}$ \\
$\mathrm{~Pb}$ & $0.105^{\mathrm{NS}}$ & $0.414^{*}$ & $0.712^{* * *}$ & $0.593^{* * *}$ & $0.145^{\mathrm{NS}}$ \\
\hline
\end{tabular}

Inter correlation of $\mathrm{Fe}, \mathrm{Pb}, \mathrm{Zn}, \mathrm{Cu}$ and $\mathrm{Ni}$ (Table $3 \mathrm{~b}$ (Fig.4b-c)) have been identified with strong correlations $(p<0.001)$ between each parameter ( $\mathrm{Fe}$ vs $\mathrm{Pb}, \mathrm{r}=0.712 ; \mathrm{Fe}$ vs $\mathrm{Ni}, \mathrm{r}=0.756 ; \mathrm{Fe}$ vs ${ }_{10} \mathrm{Zn}, \mathrm{r}=0.637$, Fe vs $\mathrm{Cu}, \mathrm{r}=0.746$; $\mathrm{Zn}$ vs $\mathrm{Cu}, \mathrm{r}=0.705$; $\mathrm{Ni}$ vs $\mathrm{Cu}$, $\mathrm{r}=0.710$ ) and are good indicators of anthropogenic sources in soils and sediments. ${ }^{20,68}$ Apeagyei et al. ${ }^{69}$ and Lopez, ${ }^{70}$ also attributed $\mathrm{Fe}, \mathrm{Pb}, \mathrm{Zn}$ and $\mathrm{Cu}$ linkages to combustion and vehicles. $\mathrm{Fe}$ and $\mathrm{Pb}$ are typically by-products of the combustion process 15 and $\mathrm{Cu}$ and $\mathrm{Zn}$ are sourced from tyre and brake linings. ${ }^{71}$ Linton et al. $^{72}$ and Robertson et al. ${ }^{20}$ demonstrated strong correlations between $\mathrm{Fe}$ and $\mathrm{Pb}$. Although use of lead in fuel had significantly reduced between the studies of Linton et al. ${ }^{72}$ and Robertson et al. $^{20}$ due to fuel additive legislation and reduction of $\mathrm{Pb}$ from 20 petroleum regulation; (1978 - EC Directive 78/611/EEC and 1981 - The Motor Fuel (Lead content of Petrol)) Regulation; limited the maximum amount of lead in petrol to $0.4 \mathrm{gl}^{-1}$ ). However, the ratio of $\mathrm{Fe} / \mathrm{Pb}$ in the magnetic fraction remains relatively consistent. ${ }^{20}$ This supports the assumption that, in addition to 25 concentrations, ratios between specific elements indicate potential source.

Table $4 \chi_{\mathrm{LF}}$ concentration data at specific sites, as referred to in Figure 5

30

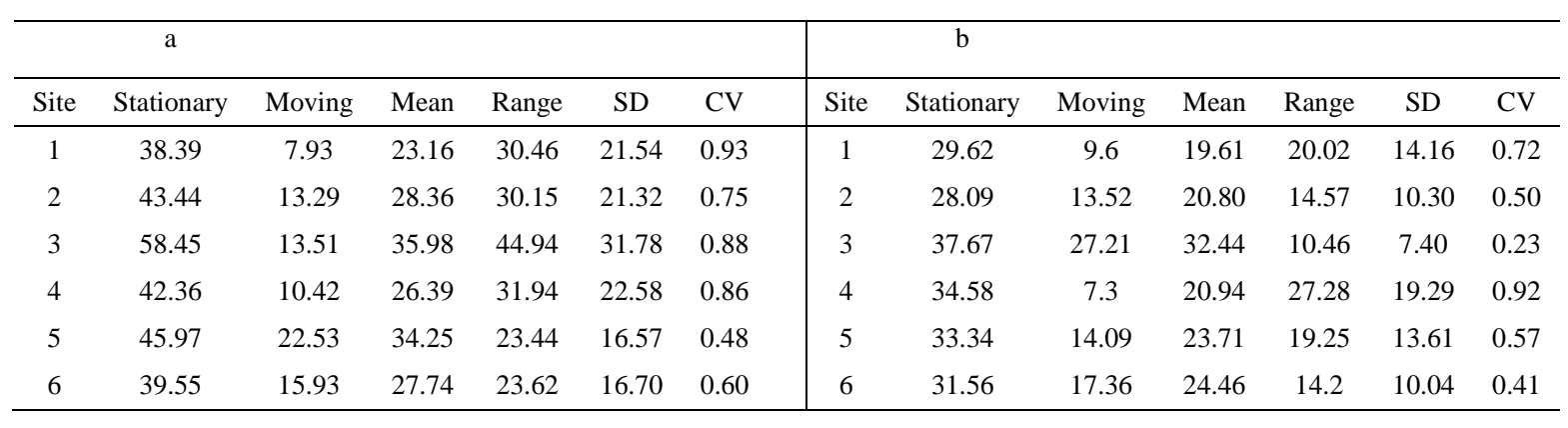

\begin{tabular}{ccccc}
\hline $\mathrm{a}+\mathrm{b}$ & & & & \\
\hline Site & $\begin{array}{c}\text { Mean } \\
\text { Stationary }\end{array}$ & $\begin{array}{c}\text { Moving } \\
\text { Mean }\end{array}$ & Range & SD \\
\hline 1 & 68.01 & 17.53 & 50.48 & 35.69 \\
2 & 71.53 & 26.81 & 44.72 & 31.62 \\
3 & 96.12 & 40.72 & 55.40 & 39.17 \\
4 & 76.94 & 17.72 & 59.22 & 41.87 \\
5 & 79.31 & 36.62 & 42.69 & 30.19 \\
6 & 71.11 & 33.29 & 37.82 & 26.74 \\
\hline
\end{tabular}



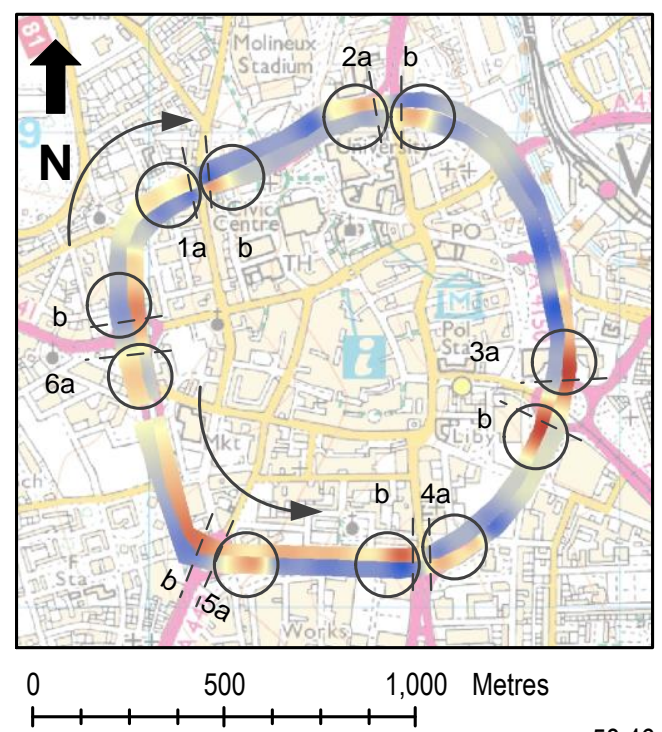

(a)
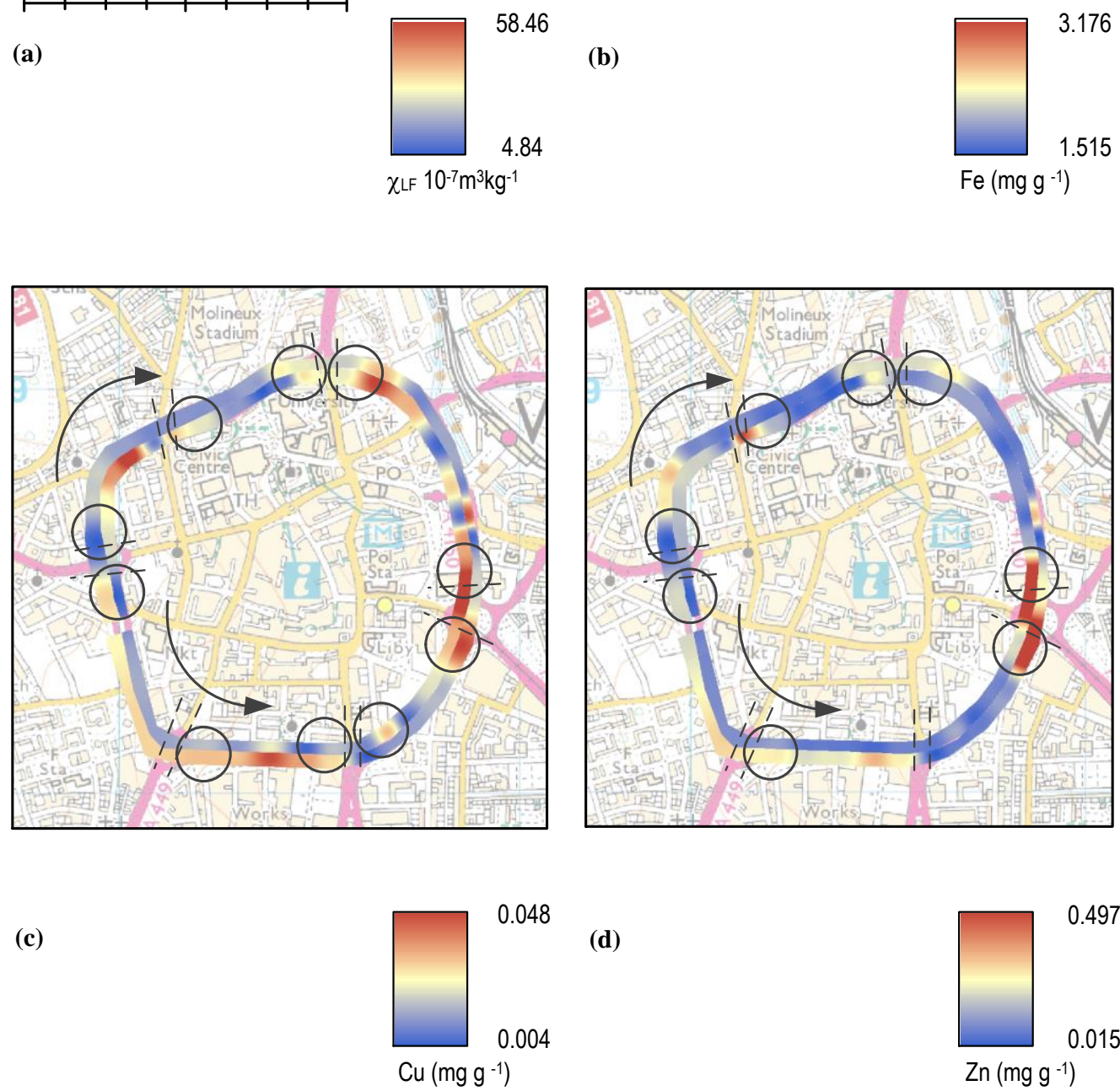

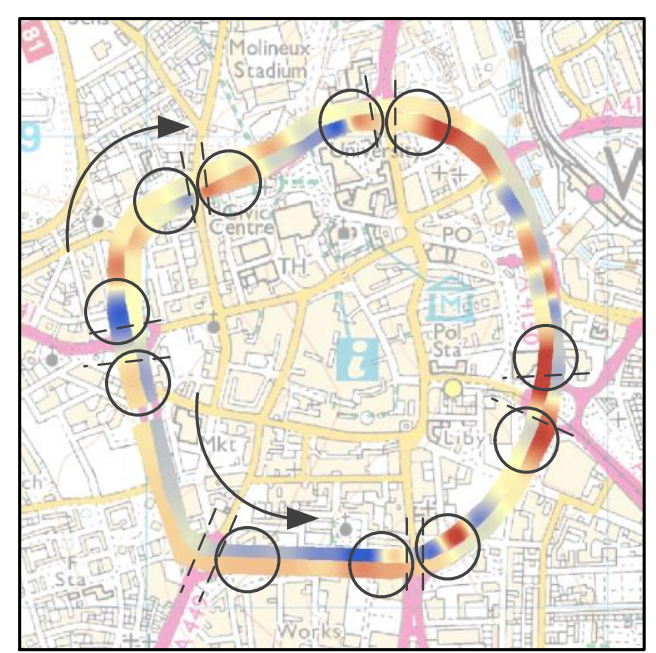

(b)

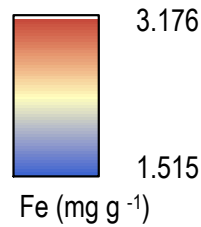

1.515

Direction of traffic flow $\quad-\ldots$ Traffic control point $\bigcirc$ Area of concentration contrast

Fig. 5 Spatial distribution of a) $\chi_{\mathrm{LF}}, \mathrm{b}$ ) Fe, c) $\mathrm{Cu}$ and d) $\mathrm{Zn}$ for Wolverhampton Ring Road soils, showing directional differences (Numerical sites refer 5 to Table 4). 
Anthropogenic influence on mineral magnetic and geochemical concentrations

Results have demonstrated how mineral magnetic measurements 5 can be used to indicate high and low concentrations of mineral magnetic and geochemical material in urban road side soil along the A4150. Table 4 (Fig. 5) further demonstrates how mineral magnetic measurements have captured inter-spatial differences, which infer traffic intensities and traffic flow direction. Inter10 spatial patterns appear to indicate high and low concentrations of magnetic minerals at specific traffic control points (areas with traffic control lights, round about systems and road junctions). Figure 5a shows $\chi_{\mathrm{LF}}$ concentrations for clockwise and anticlockwise traffic flows along the Ring Road. Results for $\chi_{\mathrm{LF}}$ 15 concentrations are presented in Table 4 and correspond to Figure 5a. High concentrations are found at traffic control points at all notable locations when compared to areas of traffic movement (Table 4, Fig. 5). Correlations of $\mathrm{Cu}$ and $\mathrm{Zn}$ suggest the influence of vehicle braking and tyre wear and show areas of high 20 concentrations near to major road junctions (Fig. 3c d, Fig. 5c, d). Although $\chi_{\mathrm{LF}}$ displays good characteristics in terms of traffic flow, not all geochemical properties correspond as well, with some crossover of material present (Fig. 5d). The relative low correspondence of $\mathrm{Zn}$ found to the north and south could be due 25 to natural processes attributed to the high susceptibility of zinc leaching and not representing original deposition. ${ }^{20}$ Due to the mineral magnetic and geochemical concentrations and associations, it is proposed that natural sources of magnetic minerals have minimal contribution to the distinct magnetic30 geochemical signal found at these sites, but are present in high concentrations due to the nature of the material and suggest some dilution of the magnetic signature. When compared to 'purer' sediment sources, like those found in Road Deposited Sediment (RDS), $\chi_{\mathrm{LF}}$ signatures of RDS are a magnitude higher than that

35 found in surrounding soils. These results indicate high inter-site variations which appear to be associated with road conditions and depositional environment.

Previous studies have identified spatial distributions of metal concentrations in urban sediments. ${ }^{15,20,23}$ Spatially metal 40 concentrations differ over small areas and can reflect contrasting levels of vehicle activity, ${ }^{1,20,23,73}$ Robertson et al. (2003), ${ }^{20}$ demonstrated the use of mineral magnetic measurements to identify spatial trends with enhanced concentrations of magnetic material in inner city samples. Moreno et al. (2003), ${ }^{58}$ and Sheng45 gao et al. (2008), ${ }^{59}$ identified high mineral magnetic concentrations and relatively large domain sizes within urban sediments linked to areas with high traffic volumes. The mineral magnetic approach demonstrated here shows some potential for application of initial assessment to potential urban pollution 50 hotspots. This study has shown primarily mineral magnetic measurements giving an indication of Fe within a sample. With the resultant concentration of $\mathrm{Fe}$ and depositional environment reflecting other contributing elements to that sample. However, caution should be used when using these methods to identify 55 specific geochemical signatures and at this time should only be used as an estimation of potential metal loading.

\section{Conclusions}

Analyses indicate magnetic concentration parameters could be ${ }_{60}$ potentially employed as a suitable pollution proxy for urban soils. Of the three magnetic parameters, $\chi_{\mathrm{LF}}$ and $\chi_{\mathrm{ARM}}$ has the strongest and most significant correlations $(p<0.001)$ with $\mathrm{Fe}, \mathrm{Pb}, \mathrm{Zn}$ and $\mathrm{Cu}$ and with inter-geochemical correlation suggesting anthropogenic input, with Fe loading dominating the signature. ${ }_{65}$ Spatial variation has been identified at inter-site scales and shows the potential for sensitive small area sampling. Low levels of $\chi_{\mathrm{FD} \%}$ and $\mathrm{MD}$ mineralogy further suggest anthropogenic influences. In most cases, these data associations follow the predictable trends of other environmental studies. Given the 70 speed, low-cost and sensitivity of the measurements, this suggests magnetic techniques could be used as a rapid alternative exploratory technology for initial assessment of urban soil pollution investigations.

\section{Acknowledgements}

All authors thank the University of Wolverhampton School of Applied Sciences for unlimited access to analytical facilities. Special thanks go to David Townrow for his time and XRF expertise.

80

\section{References}

1 C. Perry and K. Taylor Environmental Sedimentology, Blackwell Publishing, Oxford (2007).

852 W. Wilcke and M. Kaupenjohann, Heavy metal distribution between soil aggregate core and surface fractions along gradients of deposition from the atmosphere, Geoderma. 83 (1998) pp. 55-66.

3 M. van der Perk, M. Lev, A.G. Gillett, J.P. Absalom, P.A. Burrough, N.M.J. Crout, E.K. Garger, N. Semiochkina, Y.V. Stephanishin and G. Voigt, Spatial modelling of transfer of long-lived radionuclides from soil to agricultural products in the Chernigov region, Ukraine. Ecological Modelling. 128 (2000), pp. 35-50.

954 B. Maliszewska-Kordybach, B. Smreczak and S. Martyniuk, The effect of polycyclic aromatic hydrocarbons $(P A H)$ on microbial properties of soils of different acidity and organic matter content, Rocz. Glebozn. 3 (2000), pp. 5-18.

5 J.C. Klamer, W. Hegeman and F. Smedes, Comparison of grain size correction procedures for organic micropollutants and heavy metals in marine sediments, Hydrobiologia. 208 (1990), pp.213-220.

6 S.C. Rowat, Incinerator toxic emissions: a brief summary of human health effects with a note on regulatory control,

$1057 \begin{aligned} & \text { Medical Hypotheses. } 52 \text { (1999), pp. 389-396. } \\ & \text { J. Rusiecki, A. De Roos, W.J. Lee, M. Dosemeci, J. Lubin, }\end{aligned}$ J.A. Hoppin, A. Blair and M.C. Alavanja, Cancer incidence among pesticide applicators exposed to atrazine in the agricultural health study, J Natl Cancer Inst, 96 (2004), pp.1375-82

8 M. Manz, L. Weißflog, R. K"uhne and G. Schürmann. Ecotoxicological hazard and risk assessment of heavy metal contents in agricultural soils of Central Germany, Ecotoxicol Environ Saf. 42 (1999), pp. 191-201.

9 Y.G. Zhu and G. Shaw, Soil contamination with radionuclides and potential remediation, Chemosphere. 41 (2000), pp. 121128. 
10 F. Amato, M. Pandolfi, M. Viana, X. Querol, A. Alastuey and T. Moreno, Spatial and chemical patterns of PM10 in road dust deposited in urban environment, Atmospheric Environment. 43 (2009), pp. 1650-1659.

11 M.A. Anagnostopoulou and J.P. Day, Lead concentrations and isotope ratios in street dust in major cities in Greece in relation to the use of lead in petrol, Science of The Total Environment. 367 (2006), pp. 791-799.

12 L. Ferreira-Baptista and E. De Miguel, Geochemistry and risk assessment of street dust in Luanda, Angola: A tropical urban environment, Atmospheric Environment. 39 (2005), pp. 45014512.

13 L. Herngren, A. Goonetilleke and G. Ayoko, Analysis of heavy metals in road-deposited sediments, Analytica Chemica Acta. 571 (2006), pp. 270-278.

14 E. Manno, D. Varrica and G. Dongarra, Metal distribution in road dust samples collected in an urban area close to a petrochemical plant at Gela, Sicily, Atmospheric Environment. 40 (2006), pp. 5929-5941.

15 E. De Miguel, J. Llamas, E. Chacon, T. Berg, S. Larssen, O. Royset and M. Vadset, Origin and patterns of distribution of trace elements in street dust: unleaded petrol and urban lead, Atmospheric Environment. 31 (1997), pp. 2733-2740.

16 M. Murakami, F. Nakajima, H. Furumai, B. Tomiyasu and M. Owari, Identification of particles containing chromium and lead in road dust and soakaway sediment by electron probe microanalyser, Chemosphere. 67 (2007), pp. 2000-2010.

17 O. Al-Khashman, Heavy metal distribution in dust, street dust and soils from the work place in Karak industrial estate, Jordan, Atmospheric Environment. 38 (2004), pp. 6803-6812.

18 R.A. Sutherland and C.A. Tolosa, Multi-element analysis of road-deposited sediment in an urban drainage basin, Honolulu, Hawaii, Environmental Pollution. 110 (2000), pp. 483-495.

19 M. Abu-Allaban, J.A. Gillies, A.W. Gertler, R. Clayton and D. Proffitt, Tailpipe, resuspended road dust, and brake-wear emission factors from on-road vehicles. Atmospheric Environment. 37 (2003), pp. 5283-5293.

20 D.J. Robertson, K.G. Taylor and S.R. Hoon, Geochemical and mineral magnetic characterisation of urban sediment particulates, Manchester, UK, Applied Geochemistry. 18 (2003), pp. 269-282.

21 S. Kartal, Z. Aydin and S. Tokalioglu, Fractionation of metals in street sediment samples by using the BCR sequential extraction procedure and multivariate statistical elucidation of the data, Journal of Hazardous Materials. 132 (2006), pp. 8089.

22 A. Tessier, P.G.C. Cambell and M. Bisson, Sequential extraction procedure for the speciation of particulate trace metals, Analytical Chemistry. 51 (1979), pp. 844-851.

23 S.M. Charlesworth, M. Everett, R. McCarthy, A. Ordonez and E. De Miguel, A comparative study of heavy metal concentration and distribution in deposited street dusts in a large and a small urban area: Birmingham and Coventry, West Midlands, UK. Environment International. 29 (2003), pp. 563-573.

24 Y. Han, J. Cao, E.S. Posmentier, K. Fung, H. Tian and Z. An, Particulate-associated potentially harmful elements in urban road dusts in Xi'an, China, Applied Geochemistry. 23 (2008), pp. 835-845.

25 S. Xie, J.A. Dearing, J.F. Boyle, J. Bloemendal and A.P. Morse, Association between magnetic properties and element concentrations of Liverpool street dust and its implications. Journal of Applied Geophysics. 48 (2001), pp. 83-92.

26 R. Thompson and F. Oldfield, Environmental Magnetism, Allen \& Unwin, London, (1986).

27 C.A. Booth, J. Walden, A.Neal and J.P. Smith, Use of mineral magnetic concentration data as a particle size proxy: A case study using marine, estuarine and fluvial sediments in the Carmarthen Bay area, South Wales, U.K, Science of the Total Environment. 347 (2005), pp. 241-253.
28 F. Oldfield, N. Richardson, P.G. Appleby and L. Yu, ${ }^{241} A m$ and ${ }^{137} \mathrm{Cs}$ activity in fine grained saltmarsh sediments from parts of the N.E. Irish sea shoreline, Journal of Environmental Radioactivity. 19 (1993), pp. 1-24.

29 F. Oldfield and L. Yu, The influence of particle size variations on the magnetic properties of sediments from the northeastern Irish Sea, Sedimentology. 41(1994), pp. 1093-1108.

30 J. Clifton, P. McDonald, A. Plater and F. Oldfield, Derivation of a grain-size proxy to aid the modelling and prediction of radionuclide activity in salt marshes and mud flats of the Eastern Irish Sea. Estuarine, Coastal and Shelf Science. 48 (1999), pp. 511-518.

31 W. Zhang, L. Yu, M. Lu, S.M. Hutchinson and H. Feng, Magnetic approach to normalizing heavy metal concentrations for particle size effects in intertidal sediments in the Yangtze Estuary, China, Environmental Pollution. 147 (2007), pp. 238244.

32 A. Schmidt, R. Yarnold, M. Hill and M. Ashmore, Magnetic susceptibility as proxy for heavy metal pollution: a site study, Journal of Geochemical Exploration, 85 (2005), pp. 109-117.

33 C.A. Booth, C.M. Winspear, M.A. Fullen, A.T. Worsley, A.L. Power and V.J. Holden, A pilot investigation into the potential of mineral magnetic measurements as a proxy for urban roadside particulate pollution, Air Pollution XV. 101(2007), pp. 391-400.

34 C.J. Crosby, C.A. Booth, A.T. Worsley, M.A. Fullen, D.E. Searle, J.M. Khatib and C.M. Winspear, Application of mineral magnetic concentration measurements as a particle size proxy for urban road deposited sediments, In: Air Pollution XVII, (Editors) C.A. Brebbia \& V. Popov, WIT press, (2009), pp. 153-162.

35 A.L. Power, A.T. Worsley, C.A. Booth and K.M. Farr, Preliminary insights into magneto-biomonitoring (Tilia europaea and Acer pseudoplatanus) as an alternative roadside particulate air pollution technology, Air Pollution XIV. 86 (2006), pp. 525-534.

36 J. Clifton, P. McDonald, A. Plater and F. Oldfield, Relationships between radionuclide content and textural properties in Irish Sea intertidal sediments, Water Air Soil Pollution. 99 (1997), pp. 209-16.

37 S. Xie, J.A. Dearing, J. Bloemandal and J.F. Boyle, Association between the organic matter content and magnetic properties in street dust, Liverpool, UK, Science of the Total Environment. 241 (1999), pp. 205-214.

38 S. Xie, J.A. Dearing and J. Bloemandal, The organic matter content of street dust in Liverpool, UK and its association with dust magnetic properties, Atmospheric Environment. 34 (2000) pp. 269-275.

39 P.J.P. Bonnett, P.G. Appleby and F. Oldfield, Radionuclides in coastal and estuarine sediments from Wirral and Lancashire, Science of the Total Environment. 70 (1998), pp. 215-236.

40 S.M. Hutchinson and D. Prandle, Siltation in the saltmarsh of the Dee Estuary derived from 137Cs analysis of shallow cores, Estuarine and Coastal Shelf Science. 38 (1994), pp. 471- 478.

41 V.F. Shilton, C.A. Booth, P. Giess, D.J. Mitchell and C.D. Williams, Magnetic properties of urban street dust and its relationship to organic matter content in the West Midlands, U.K Atmospheric Environment. 39 (2005), pp. 3651-3659.

42 E. Petrovský and B.B. Ellwood, Magnetic monitoring of airland and water-pollution. In: B.A. Maher and R. Thompson (Editors), Quaternary Climates, Environments and Magnetism, Cambridge University Press, (1999).

43 M.J. Dekkers, Environmental magnetism: an introduction, Geologie en Mijnbouw, 76 (1997), pp. 163-182.

44 J. Dearing, Magnetic susceptibility. In: J. Walden, J.P. Smith and F. Oldfield, (Editors). Environmental Magnetism: a practical guide, Technical Guide, No. 6, Quaternary Research Association, London, (1999) pp. 35-62. 
45 P.J. Flanders, Collection, measurement, analysis of airborne magnetic particulates from pollution in the environment, Journal of Applied Physics, 75 (1994), pp. 5931-5936.

46 U. Kukier, C.F. Ishak, M.E. Sumner and W.P. Miller, Composition and element solubility of magnetic and nonmagnetic fly ash fractions, Environmental Pollution. 123 (2003), pp. 255-266.

47 A.R. Muxworthy, J. Matzka, A.F. Davila and N. Petersen, Magnetic signature of daily sampled urban atmospheric particles, Atmospheric Environment, 37 (2003), pp. 41634169.

48 J. Matzka and B.A. Maher, Magnetic biomonitoring of roadside tree leaves: identification of spatial and temporal variations in vehicle-derived particulates, Atmospheric Environment. 33 (1999), pp. 4565-4569.

49 J. Walden, F. Oldfield and J.P. Smith, Environmental Magnetism: A Practical Guide. Quaternary Research Association, London, (1999).

50 C.J.Crosby, M.A. Fullen and C.A. Booth, Mineral magnetic measurements as a poarticle size proxy for urban roadside soil pollution (Part 1), Environmental Science: Processes and Impacts. (2014), in press.

51 J.F. Boyle, Rapid elemental analysis of sediment samples by isotope source XRF, Journal of Palaeolimnology. 200 (2000), PP. 213-221.

52 X.F. Hu, Y. Su, R. Ye, X.Q. Li and G.L. Zhang, Magnetic properties of the urban soils in Shanghai and their environmental implications, Catena. 70 (2007), pp. 428-436.

53 T. Yang, Q.S. Liu, L.S. Chan and G.D. Gao, Magnetic investigation of heavy metals contamination in urban topsoils around the East Lake, Wuhan, China. Geophysics Journal International. 171 (2007), pp. 603-612.

54 J.A. Dearing, K.L. Hay, M.J. Baban, A.S. Huddleston, E.M.H. Wellington and P.J. Loveland, Magnetic susceptibility of soil; an evaluation of conflicting theories using a national data set, Geophysical Journal International. 127 (1996), pp. 728-734.

55 B.A. Maher, Characterisation of soils by mineral magnetic measurements, Physics of the Earth and Planetary Interiors. 42 (1986), pp. 76-92.

56 A. Blundell, J.A. Hannam, J.A. Dearing and J.F. Boyle, Detecting atmospheric pollution in surface soils using magnetic measurements: A reappraisal using an England and Wales database, Environmental Pollution. 157 (2009), pp. 2878-2890.

57 J.A. Dearing, Environmental Magnetic Susceptibility. Chi Publishing, Kenilworth, (1994).

58 E. Moreno, L. Sagnotti, J. Dinarès-Turell, A. Winkler and A. Cascella, Biomonitoring of traffic air pollution in Rome using magnetic properties of tree leaves, Atmospheric Environment. 37 (2003), pp. 2967-2977.

59 L. Sheng-Gao, B. Shi-Qiang and F. Li-Xia, Magnetic properties as indicators of $\mathrm{Cu}$ and $\mathrm{Zn}$ contamination in soils, Pedosphere. 18 (2008), pp. 479-485.

60 T. Yang, Q. Liu, H. Li, Q. Zeng and L. Chan, Anthropogenic magnetic particles and heavy metals in the road dust: Magnetic identification and its implications, Atmospheric Environment. 44 (2010), 1175-1185.

61 F. Fujiwara, R.J. Rebagliati, L. Dawidowski, D. Gómez, G. Polla, V. Pereyra and P. Smichowski, Spatial and chemical megacitiy, Atmospheric Environment. 45 (2011), pp. 14971505.

62 W. Kim, S.J. Doh, Y.H. Park and S.T. Yun, Two-year magnetic monitoring in conjunction with geochemical and electron microscopic data of roadside dust in Seoul, Korea, Atmospheric Environment. 41 (2007), pp. 7627-7641.
63 P.R. Beckwith, J.B. Ellis, D.M. Revitt and F. Oldfield, Heavy metal and magnetic relationships for urban source sediments, Physics of The Earth and Planetary Interiors. 42 (1986), pp.67-75.

64 K.L. Hay, J.A. Dearing, S.M.J. Baban and P. Loveland, A preliminary attempt to identify atmospherically-derived pollution particles in English topsoils from magnetic susceptibility measurements, Physics and Chemistry of the Earth. 22 (1987), pp. 207-210.

65 V.M. Georgeaud, P. Rochette, J.P. Ambrosi, D. Vandamme and D. Williamson, Relationship between heavy metals and magnetic properties in a large polluted catchment: the Etang de Berre (South of France), Physics and Chemistry of the Earth. 22 (1987), pp. 211-214.

66 S.G. Lu and S.Q. Bai, Study on the correlation of magnetic properties and heavy metals content in urban soils of Hangzhou City, China, Journal of Applied Geophysics. 60 (2006), pp. 1-12.

8567 G. Wang, F. Oldfield, D. Xia, F. Chen, X. Liu and W. Zhang, Magnetic properties and correlation with heavy metals in urban street dust: A case study from the City of Lanzhou, China, Atmospheric Environment. 46 (2012), pp. 289-298.

68 R.M. Harrison, A.M. Jones and R.G. Lawrence, Major component composition of PM10 and PM2.5 from roadside and urban background sites, Atmospheric Environment. 38 (2004), pp. 4531-4538.

69 E. Apeagyei, M.S. Bank and J.D. Spengler, Distribution of heavy metals in road dust along an urban-rural gradient in Massachusetts, Atmospheric Environment. 45 (2011), pp. 2310-2323.

70 J.M. López, M.S. Callén, R. Murillo, T. Garcia, M.V. Navarro, M.T. de la Cruz and A.M. Mastral, Levels of selected metals in ambient air PM10 in an urban site of Zaragoza (Spain), Environmental Research. 99 (2005), pp. 58-67.

71 J.Y. Kim, J.H. Myung, J.S. Ahn and H.T. Chon, Heavy metal speciation in dusts and stream sediments in the Taejon area, Korea, Journal of Geochemical Exploration. 64 (1998), pp. 409-419.

10572 R.W. Linton, D.F.S. Natusch, R.L. Solomon and C.A. Evans, Physicochemical characterization of lead in urban dust: a microanalytical approach to lead tracing, Environmental Science and Technology. 14 (1980), pp. 159-164.

73 S.M. Nageotte and J.P. Day, Lead concentrations and isotope ratios in street dust determined by electrothermal atomic absorption spectrometry and inductively coupled plasma mass spectrometry, Analyst. 123 (1998), pp. 59-62.

\section{${ }^{a}$ CBE Loughborough University LE11 3TU, United Kingdom. 115 E-mail:c.j.crosby@lboro.ac.uk \\ ${ }^{b}$ FSE, University of Wolverhampton, WV1 1LY, United Kingdom \\ ${ }^{c} D C P$, University of the West of England, BS16 1QY, United Kingdom.}

$\dagger$ Electronic Supplementary Information (ESI) available: [details of any 120 supplementary information available should be included here]. See DOI: $10.1039 / b 000000 x /$

\$ Footnotes should appear here. These might include comments relevant to but not central to the matter under discussion, limited experimental and spectral data, and crystallographic data.

1251 A. Name, B. Name and C. Name, Journal Title, 2000, 35, 3523; A. Name, B. Name and C. Name, Journal Title, 2000, 35, 3523. 